\title{
Ethical, religious and factual beliefs about the supply of emergency hormonal contraception by UK community pharmacists
}

\author{
Richard J Cooper, Paul Bissell, Joy Wingfield
}

\begin{abstract}
Background and methodology Community pharmacists' role in the sale and supply of emergency hormonal contraception (EHC) represents an opportunity to increase EHC availability and utilise pharmacists' expertise but little is known about pharmacists' attendant ethical concerns. Semi-structured qualitative interviews were undertaken with 23 UK pharmacists to explore their views and ethical concerns about EHC.

Results Dispensing EHC was ethically acceptable for almost all pharmacists but beliefs about selling EHC revealed three categories: pharmacists who sold EHC, respected women's autonomy and peers' conscientious objection but feared the consequences of limited EHC availability; contingently selling pharmacists who believed doctors should be first choice for EHC supply but who occasionally supplied and were influenced by women's ages, affluence and genuineness; non-selling pharmacists who believed EHC was abortion and who found selling EHC distressing and ethically problematic. Terminological/factual misunderstandings about EHC
\end{abstract}

\section{Introduction}

This article considers the role of community pharmacists in the sale and supply of emergency hormonal contraception (EHC) in the UK and, in particular, explores the ethical, religious and factual beliefs of pharmacists and their potential effect upon the availability of EHC in UK pharmacies. The findings of a qualitative study are presented and it is argued that although UK pharmacy sales and supplies of EHC represent opportunities for pharmacists to contribute to public health and also engage in new professional challenges, a range of ethical, religious and knowledge concerns identified in the study may affect the availability of EHC for UK female customers.

In the UK, community pharmacists have been involved in the dispensing of EHC for more than 15 years, when it was originally a combined oestrogen and progestogen formulation. But with the introduction of a progestogenonly product in 2000 , EHC became available for supply by pharmacists in the form of patient group directions (PGD). ${ }^{1}$ This was soon followed by the reclassification of EHC to a 'pharmacy' medicine which, branded as Levonelle ${ }^{\circledR}$, could be sold from pharmacies without a prescription or the need for PGD, with the aim of

Division of Social Research in Medicines and Health,

The School of Pharmacy, University of Nottingham,

Nottingham, UK

Richard J Cooper, PhD, MA, Research Fellow

Joy Wingfield, MPhil, LLM, Professor

Section of Public Health, School of Health and Related Research (ScHARR), University of Sheffield, Sheffield, UK Paul Bissell, PhD, MA, Senior Lecturer

Correspondence to: Dr Richard J Cooper, Division of Social Research in Medicines and Health, The School of Pharmacy, University of Nottingham, University Park, Nottingham NG7 2RD, UK. E-mail: richard.cooper@nottingham.ac.uk were common and discussing ethical issues was difficult for most pharmacists. Religion informed non-selling pharmacists' ethical decisions but other pharmacists prioritised professional responsibilities over their religion.

Discussion and conclusions Pharmacists' ethical views on EHC and the influence of religion varied and, together with some pharmacists' reliance upon non-clinical factors, led to a potentially variable supply, which may threaten the prompt availability of EHC. Misunderstandings about EHC perpetuated lay beliefs and potentially threatened correct advice. The influence of subordination and non-selling pharmacists' dispensing EHC may also lead to variable supply and confusion amongst women. Training is needed to address both factual/terminological misunderstandings about EHC and to develop pharmacists' ethical understanding and responsibility.

Keywords emergency contraception, ethics, pharmacists, religion

J Fam Plann Reprod Health Care 2008; 34(1): 47-50

(Accepted 8 July 2007)

\section{Key message points}

- Sales of emergency hormonal contraception (EHC) from UK community pharmacies may be influenced by ethical objection, religious beliefs and non-clinical factors but dispensing EHC was almost always ethically acceptable.

- Three categories of pharmacists emerged: a majority who found EHC sales unproblematic, those who sold contingently and a minority who were ethically and religiously opposed to selling EHC.

- Factual and terminological errors and a marked difficulty in discussing ethical issues were identified, necessitating further education.

improving timely access to EHC by women. Although the overall amount of EHC issued in the UK has remained relatively static, around $45 \%$ of EHC supplies now occur from pharmacies but almost $10 \%$ of women still report difficulty in obtaining EHC. ${ }^{2}$ These statistics, coupled with several popular press reports of pharmacists refusing to sell $\mathrm{EHC}^{3}$ and ongoing debates as to whether pharmacists may conscientiously object to EHC, ${ }^{4-6}$ mean that research is needed to explore issues surrounding ethics, religion and the availability of EHC for sale and supply in pharmacies.

Pharmacy supply of EHC has prompted research ${ }^{1}$ and the experiences and attitudes of pharmacists have been explored ${ }^{7-10}$ but no studies have specifically explored pharmacist EHC supplies in an ethical or religious context. Occasional ethical concerns have been identified and Blackwell et al., ${ }^{11}$ for example, reported moral objection to EHC sales in $2.6 \%$ of pharmacists, D'Souza and Bounds 12 reported conscientious objection amongst one in five pharmacists whilst Wearn et al. ${ }^{13}$ argued that "ethical reasons did not appear to be a major factor that would affect pharmacists' ability to supply EHC'. The objective of this article is to gain a greater understanding of the ethical, religious and practical issues surrounding EHC 
sales and supply in the UK and in so doing help inform discussions amongst the media, academia and professions concerning pharmacists' involvement in this important area of health care.

\section{Methods}

The qualitative study reported on here involved semistructured interviews with 23 pharmacists, recruited from two counties in the North of England, UK, between January 2004 and July 2005. The research was part of a larger study investigating the ethical problems encountered by UK community pharmacists and how such problems were dealt with. Recruitment, interviewing and analysis were undertaken by one of the authors. A semi-structured interview method was used to allow pharmacists to describe issues as fully as possible, valuing the richness and complexity of potential responses but also allowing the researcher to challenge and clarify responses.

Sampling was purposive to obtain representation in terms of age, gender, ethnicity and employment status. In particular, the aim was to recruit pharmacists from a range of employers and a sample grid was produced to enable a systematic purposive approach. Pharmacists were approached by either an initial telephone call or introductory letter, and a follow-up telephone call was arranged a few weeks later. Participants were asked prior to interview to identify ethical issues they had experienced in their work and to be prepared to discuss them. Prompting was avoided where possible but the subject of EHC was raised if pharmacists did not mention it spontaneously, and their views on conscientious objection were also solicited. Transcribed interviews were analysed in two key ways. First, framework analysis involving an ethical decisionmaking model ${ }^{14}$ was used to gain an understanding of how community pharmacists identified ethical problems, reasoned and acted. Second, the techniques of constant comparison and deviant case analysis were utilised in relation to the interview data and all emergent themes were coded. Analysis was performed by one researcher but with subsequent discussions with the other researchers. The sample size was determined by theoretical saturation being reached when no further themes emerged from interviews.

\section{Ethical approval}

Relevant ethics committee approval was obtained for this study from the University of Nottingham School of Pharmacy.

\section{Results}

Following analysis of interviews, a number of ethical issues emerged amongst pharmacists, although it was apparent that many of the pharmacists found it difficult to discuss and describe ethical issues, values and attendant reasoning. Dispensing EHC was ethically unproblematic for all but one pharmacist but a range of concerns emerged in relation to selling EHC and three broad categories of pharmacist were identified: those who found selling EHC ethically unproblematic, those who were completely opposed to selling EHC and those who decided contingently and supplied EHC in some situations but not others. These three categories encompassed several more specific ethical, but also religious and practical, concerns and these are now described in more detail, illustrating a complex and occasionally conflicting range of beliefs and values about EHC.

\section{EHC-selling pharmacists}

The first category of pharmacist did not identify EHC as being ethically problematic and routinely sold and dispensed EHC in their community pharmacy work. This category included most (i.e. 16) of the pharmacists in the study, but although these pharmacists were usually prompted about EHC supplies during interviews, this did not mean that there was an absence of ethical concerns about EHC and three key issues emerged for these pharmacists. Several argued that it was important for a woman to be able to decide upon her treatment and such views appeared to involve implicit appeals to female customers' autonomy. As one pharmacist noted:

"Which is more wrong? Terminating the life of an unborn fetus or making that woman go through with a pregnancy that she doesn't want and then you end up with another person in the world who isn't wanted ... it's up to the individual and I don't think that we should be sitting and making judgments like that for them, it's up to them." (Michael)

Although frequently not couched in ethical argument or references to values, many of the pharmacists in this study believed that EHC was not an ethical problem for them. Furthermore, several EHC-selling pharmacists also expressed some form of religious faith but argued that whilst this was important for them, their professional responsibilities took precedence. Prioritising women's right to choose treatment such as EHC appeared to be centred upon a liberal value of respecting others' opinions and this was reflected in a second ethical issue identified amongst pharmacists who sold EHC, namely their respect for their pharmacist peers who did not want to sell EHC. When asked about non-supplying pharmacists and also conscientious objection, all the pharmacists who sold EHC argued that the decision as to whether to supply EHC should be left to individual pharmacists. However, several pharmacists qualified their remarks by raising concerns about the possible consequences of a pharmacist not supplying EHC. Situations were described where it was argued women might be inconvenienced or even denied treatment and this often involved pharmacists' anecdotal experiences, when a non-selling locum pharmacist had covered their day off:

"But I think that as long as there are other places they [female customers] can go to then it's not a problem. During the week it's not a problem as they can just go down the road but when it's a Saturday and stuff then, no, I don't think it's fair because it's not their fault - they're [non-selling pharmacists] thinking too much of themselves." (Clare)

Pharmacists identified weekends as a particular concern since access to general medical practitioners, who could provide a prescription for EHC at such times, is now very limited in England, due to contractual changes in how doctors are remunerated, and in addition there has been an associated reduction in the number of pharmacies opening. The third emergent issue in relation to pharmacists who did sell EHC was that it appeared to be valued instrumentally by some in terms of benefiting the pharmacy profession. UK community pharmacists are presently undergoing a number of changes in their work and are increasingly being encouraged to provide additional services such as medicine use reviews, diagnostic testing and prescribing. This led one pharmacist to comment:

"EHC I have welcomed. I think it's great. I think it really has enhanced the profession and it has provided a model we should work to for other areas". (Robert)

\section{Contingently selling pharmacists}

A second category of four pharmacists identified in this study sold EHC contingently, that is they believed there 
were only certain circumstances in which EHC sales were justified. Although this may be said of EHC generally wherein supplying pharmacists could take into account age, time of presentation and pregnancy as reasons not to supply, the pharmacists in this second category cited other factors that related more to the patients' circumstance and background than obvious and clinically relevant indications. First, the location of a pharmacy and hence type of customer frequenting a pharmacy was significant for several pharmacists, and appeared to involve concerns about the relative deprivation in a locality's population and also the customer's relative affluence:

"I don't particularly agree with abortion and this [EHC] is a form of it. But I do think that I suppose at the moment I see a lot of the problems that come from having children and them being born out of marriage to young parents from irresponsible sex, basically. So, that has quite heavily influenced me at the moment and I do sell it ... but I don't know whether I would gauge that on the environment that I was working in. This next job I'm going to is in a very nice area with a lot of, sort of quite wealthy people ...". (Andrew)

The age and type of customer was also a factor for some respondents and appeared to be based upon perceptions about the motivation for using EHC. For one pharmacist this involved a perception that older customers were genuine and less likely to try to obtain EHC repeatedly, unlike younger women:

"So if somebody comes in here for the morning-after pill, I'll say 'Well, you're going to have to go and see your doctor' ... I will sell to the elder woman who's obviously had an accident. But anybody that looks under twenty-five, no way because the other thing is that I don't think that we should be giving massive doses of hormones to young and growing females. I don't think it's medically sound and I worry that they talk to their mates at school ... and they'll go from shop to shop each month." (Larry)

Many contingently selling pharmacists felt pharmacies were not the most appropriate place to obtain EHC and many favoured the doctor and hence would routinely refer women to a doctor, except where this was not possible. In such circumstances - often evenings and weekends - such pharmacists argued that they would sell EHC. In contrast to the supplying pharmacists, some contingently selling pharmacists perceived EHC to have a negative value on the profession and again saw EHC instrumentally. Such pharmacists appeared to overlook the possible benefits to women and viewed EHC sales instrumentally in terms of its impact upon pharmacy more generally and UK governmental policy:

"I'm not happy with supplying EHC where we could supply many other things and I think it's been a ploy by the government to use pharmacists to reduce teenage pregnancies. So we're used, we're just basically pawns in the government game, really." (Shahid)

\section{Non-selling pharmacists}

A third category of three pharmacists identified in the interviews were completely opposed to the sale of EHC and such pharmacists often spontaneously identified EHC sales as an example of an ethical problem in their work. The decision to deregulate EHC, such pharmacists noted, had led to considerable ethical concern and anxiety for them since they believed it to be a form of abortion, and both ethically and also religiously wrong. Although EHC sales were ethically problematic for only a few pharmacists in this study, what was apparent was that requests by women to purchase EHC had led to considerable distress and ethical concern:

"I think it causes an abortion. They say it doesn't but that's what I think and I'm just totally against that, which originally comes from a religious belief ... and when it became that it was coming over the counter, I thought 'Oh, no, am I going to be forced into doing something that I don't want to do?"'

“... I've just got to send them a bit further. I just cop out and say 'I haven't got any' [or] I would avoid the issue and having to argue or present my case." (Hilary)

Despite being passive and lying to customers about not having supplies of EHC, this pharmacist was not opposed to referring a customer to another pharmacy - indeed this offered a convenient solution to their ethical distress - but even such referrals were problematic for another pharmacist:

"If we have an objection to it, we need not provide contraception but we must tell the patient where else they can go to get it. Now even that, telling someone else where to go to get the morning-after pill which to me is a means of terminating life, is almost as bad as doing it yourself." (Christopher)

Although recognising that the Royal Pharmaceutical Society ${ }^{15}$ had issued guidance on conscientious objection, this offered little help to this pharmacist because he wanted to explain to customers why he could not supply and recalled one incidence where both he and a customer had become upset because he could not explain his religious beliefs. However, what was apparent for all but one pharmacist in this study was that dispensing EHC on a prescription was neither ethically nor professionally problematic. In such instances, non-selling pharmacists argued that they were prepared to supply EHC since a prescribing doctor was taking the responsibility for the supply:

"Yea, I'll let somebody else make that decision - but not me. I mean, maybe that's a cop-out, I don't know, but that's how I feel." (Hilary)

This variability in supply of EHC by sale or prescription was central to another non-selling pharmacist's reason for not stocking any EHC at all, either for dispensing from prescriptions or for sale. Although his religious faith was important for him, this pharmacist argued that the decision not to stock EHC was neither religious nor ethical, but pragmatic. He managed a pharmacy that was open long hours and hence used several other pharmacists in his absence, some of whom would supply and some who would not. Hence, a decision not even to stock EHC avoided confusion amongst the public and allowed for consistency, despite the pharmacy receiving many requests for $\mathrm{EHC}$ due to its extended opening hours.

\section{Discussion}

There appeared to be a range of different beliefs and values involved in pharmacists' decisions as to whether to sell EHC, despite most pharmacists in this study favouring sales and all but one finding dispensing unproblematic. Interestingly, none of the pharmacists commented on the relatively high cost of Levonelle in the UK and potential ethical issues such as the commercial exploitation of this recently reclassified medicine. ${ }^{16}$ The findings of this study, although not necessarily generalisable to all UK 
pharmacists despite the use of purposive sampling, indicate that issues such as religious faith are more complex than some of the popular press reports about pharmacists and EHC suggest. Faith could conflict with pharmacists' professional duties and the wishes of customers but did not necessarily prevent EHC sales for some. However, for others, it led to ethical opposition to selling EHC but not to dispensing it - an inconsistency in supply that may cause confusion amongst women. Of perhaps more concern though were some pharmacists' decisions not to sell EHC based upon perceptions of customers as being more likely to abuse EHC based upon age, wealth or locality. This may have a detrimental effect upon the availability of EHC from pharmacies and perpetuates erroneous and negative stereotypes of some women, especially those younger and single. ${ }^{17}$

A linked and worrying concern to emerge from this study was a widespread confusion over both terminology and the pharmacological action of EHC. Disappointingly, many pharmacists continued to use the popularised term 'morning-after pill' despite this being a somewhat misleading term and one which could potentially stop women seeking EHC treatment up to 72 hours post coitus. ${ }^{18}$ Additional unsupported beliefs that high progestogen doses were harmful or that pharmacy EHC availability would lead to repeated use or increased promiscuity were disappointing findings in this study and have emerged in previous research findings and may negatively affect the ability of women to obtain treatment. ${ }^{8}$ Further terminological concerns involved several pharmacists' claims that EHC would lead to the ending of the life of a fetus and several non-supplying pharmacists referred to the word 'abortion' in relation to EHC. Although several respondents conceded that this was not accepted medical knowledge, the use of the word 'abortion' appeared to constitute a deliberate 'moral vocabulary' and hence an ethical resource that they believed could not be challenged any further ${ }^{19}$ - and arguably could be linked to the difficulty they had in discussing ethical issues and values.

A number of implications for practice arise from this study and these concern pharmacists' knowledge base, ethical understanding and their responsibilities in the delivery of health care. First, the persistence of lay terminology and incorrect facts about EHC may be detrimental not only to customers (who may not fully understand the facts about $\mathrm{EHC}^{2}$ and hence need correct information from health care professionals) but also to the debate about pharmacists' role in EHC supply. Pharmacists must be provided with educational resources to address these misunderstandings about EHC, especially since they have been used to argue that pharmacists should always supply EHC. ${ }^{4}$ Second, it is possible to view EHC as providing pharmacists with an opportunity for ethical engagement, in what has been argued is an increasingly morally sequestrated society, ${ }^{20}$ and EHC represents a focus, to help develop ethical value awareness and promote debate. ${ }^{21}$ Research has indicated that pharmacists view ethical issues in a legalistic, self-interested way ${ }^{22}$ - which may explain their observed difficulty in articulating ethical issues in this study - and EHC offers opportunities to discuss ethical issues and reflect upon patients' and pharmacists' values. Third, some pharmacists' belief that doctors should routinely be consulted to obtain EHC, coupled with some pharmacists dispensing but not selling of EHC, lead to concerns about pharmacists' subordination to doctors and the abrogation of ethical and professional responsibility. If pharmacists do not develop ethical and professional responsibility and equip themselves with the necessary facts about EHC, then proposed developments such as the advance supply of EHC, ${ }^{23}$ for example, could result in pharmacists' role in the sale and supply of EHC being undermined.

Statements on funding and competing interests Funding None identified.

Competing interests None identified.

\section{References}

1 Anderson C, Blenkinsopp A. Community pharmacy supply of emergency hormonal contraception: a structured literature review of international evidence. Hum Reprod 2006; 21: 272-284.

2 Office for National Statistics. Contraception and Sexual Health, 2005/06 (Omnibus Survey Report No. 30). 2006. http:// www.statistics.gov.uk/downloads/theme_health/contraception 2005-06.pdf [Accessed 2 May 2007].

3 Stokes P. Mother is denied Pill by Muslim pharmacist. The Daily Telegraph, 14 October 2006.

4 Cantor J, Baum K. The limits of conscientious objection: may pharmacists refuse to fill prescriptions for emergency contraception? N Engl J Med 2004; 351: 2008-2012.

5 Hepler C. Balancing pharmacists' conscientious objection with their duty to serve. J Am Pharm Assoc 2005; 45: 434-436.

6 Manasse $\mathrm{H}$. Conscientious objection and the pharmacist. Nature 2005; 308: 1558-1559.

7 Barrett G, Harper R. Health professionals' attitudes to the deregulation of emergency contraception (or the problem of female sexuality). Sociol Health IIIn 2000; 22: 197-216.

8 Seston EM, Holden K, Cantrill J. Emergency hormonal contraception: the community pharmacy perspective. J Fam Plann Reprod Health Care 2001; 27: 203-208.

9 Sommers SD, Chaiyakunapruk N, Gardner JS, Winkler J. The emergency contraception collaborative prescribing experience in Washington State. J Am Pharm Assoc 2001; 41: 60-66.

10 Bissell P, Anderson C. Supplying emergency contraception via community pharmacies in the UK: reflections on the experiences of users and providers. Soc Sci Med 2003; 57: 2367-2378.

11 Blackwell D, Cooper N, Taylor G, Holden K. Pharmacists' concerns and perceived benefits from the deregulation of hormonal emergency contraception. Br J Fam Plann 1999; 25: 100-104.

12 D'Souza R, Bounds W. Over the counter emergency contraception: a survey of pharmacists' and general practitioners' knowledge, use and views. Pharm J 2001; 266: 293-296.

13 Wearn A, Gray M, Gill P, Ewan MA, Sanghu P, Rajaei-Dehkordi Z. A postal survey to assess the view of community pharmacists on the deregulation of emergency hormonal contraception. Int J Pharm Pract 2001; 9(Suppl.): R58.

14 Jones TM. Ethical decision making by individuals in organisations: an issue-contingent model. Acad Manage Rev 2001; 16: 366-395.

15 Royal Pharmaceutical Society of Great Britain. Medicines, Ethics and Practice: A Guide for Pharmacists (30th edn). London, UK: Royal Pharmaceutical Society of Great Britain, 2006.

16 Anonymous. Pharmacists believe EHC is too costly. Pharm J 2003; 270: 603.

17 Hope H, Dye L, Knapp PR, Sowter JR, Raynor DK. Clare wants the morning-after pill: what do practitioners think? Int J Pharm Pract 2002; 10(Suppl.): R71.

$18 \mathrm{Ma}$ R. Emergency contraception is not just for the morning after BMJ 2006; 333: 756.

19 Lowe B. Hearts and minds and morality: analyzing moral vocabularies in qualitative studies. Qual Sociol 2002; 25: 105-123.

20 Giddens A. Modernity and Self-Identity. Self and Society in the Late Modern Age. Cambridge, UK: Polity, 1991.

21 Cribb A, Barber N. Developing Pharmacy Values: Stimulating the Debate. London, UK: Royal Pharmaceutical Society of Great Britain, 2000.

22 Cooper RJ, Bissell P, Wingfield J. Dilemmas in dispensing, problems in practice? Ethical issues and law in UK community pharmacy. Clin Ethics 2007; 2: 103-108.

23 Litt IF. Placing emergency contraception in the hands of women. JAMA 2005; 293: 98-99. 